\title{
Erratum to: Quantitative characteristics of the phases of winter dormancy of conifer species at a site in Central Siberia
}

\author{
Nina V. Pakharkova ${ }^{1} \cdot$ Hermann Heilmeier $^{2} \cdot$ Irina G. Gette $^{1} \cdot$ Elena B. Andreeva $^{3}$. \\ Alexi M. Grachev ${ }^{4} \cdot$ Nikolay A. Gaevskiy $^{1}$ Yurii S. Grigoriev ${ }^{1}$
}

Published online: 28 February 2017

(c) Botanical Society of Sao Paulo 2017

\section{Erratum to: Braz. J. Bot (2016) 39(4):1005-1014 DOI 10.1007/s40415-016-0298-3}

In this article, two paragraphs were inadvertently not included in the published version. We apologize to the authors and readers for the inconvenience. The paragraphs should have appeared at the end of 'Results and Discussion' section and read as follows:

We conclude that all of the tree species studied are characterized by different depths of dormancy. Dark-needle species especially fir are characterized by a smaller depth of dormancy and a shorter duration of dormancy. The results obtained using the method employing TICZF agree with the data on the content of abscisic acid and photosynthetic pigments. Perhaps under the conditions of climatic warming, the A. sibirica trees emerge from the forced dormancy even during the brief winter thaws, which previously have not been typical for the studied area. Water losses that arise due to the resumption of photosynthetic activity and gas exchange cannot be compensated under the winter conditions due to frozen soils, which leads to desiccation and death of the needles.

In support of suggestions by previous studies (see, e.g., Ohse et al. 2012), our study underlines the importance of further studies on the effect of changing climatic factors on tree growth and survival.
The online version of the original article can be found under doi: 10.1007/s40415-016-0298-3.

Nina V. Pakharkova

nina.pakharkova@yandex.ru

1 Siberian Federal University, Pr. Svobodny 79, Krasnoyarsk, Russia 660041

2 TU Bergakademie Freiberg, Leipziger Str. 29, 09599 Freiberg, Germany

3 State Natural Reserve "Stolby", Kar'ernaya 26a, Krasnoyarsk, Russia 660006

4 Institute of Geography of the Russian Academy of Sciences, 29 Staromonetniy Pereulok, Moscow, Russia 119017 